Ankara Ecz. Fak. Der.

$20,1-2(1999)$
J. Fac. Pharm. Ankara

$20,1-2(1999)$

Narkotik Analjeziklerin Gaz-Sivi Kromatografisi İle Ayırımı ve Miktar Tayini

The Seperation and Quantitation of the Narcotic Analgesics Using Gas-Liquid Chromatography*

Ayla Tamer**

Haluk SARGIN***

ÖZET

Narkotik analjezik ilaçların analizlerinde kullanışlı ve çabuk bir gaz kromatografik yöntem geliştirildi. Bu ilaçların kantitatif analizleri aynı deneysel şartlarda yapıldı. Kalibrasyon grafikleri çıkarıldı ve 0.01 $1 \mathrm{mg} / \mathrm{ml}$ konsantrasyon aralığında doğrusallıkları gösterildi.

\title{
SUMMARY
}

A convenient and rapid gas-chromatographic method for analysis of narcotic analgesic drugs has been developed. Quantitative analyses of these drugs have been performed with the same instrumental set-up. Calibration graphs were evaluated and showed linearity in the concentration range $0.01-1 \mathrm{mg} / \mathrm{ml}$.

Anahtar Kelimeler: Narkotik analjeziklerin analizleri, Meperidin, Metadon, Kodein, Gaz-kromatografi.

Redaksiyona verildiği tarih: 25.9.1989

* Bu çalışma III. Kimya ve Kimya Mühendisliği Simpozyumunda sunulmuştur. 17-20 Eylül 1986 Ankara.

** Analitik Kimya Anabilim Dalı, Eczacılık Fakültesi, Hacettepe Üniversitesi, ANKARA

*** Emniyet Genel Md. Kriminal Polis Lab. Daire Başkanlı̆̆ı, Anıttepe ANKARA. 
Narkotik analjezikler, bağımlılık yapan maddeler içinde yer alan ve suistimali kolay olan ilaçlardır. Bu nedenle özellikle forensik ilaç laboratuvarlarında analizleri ayrı bir önem taşır (1-3). Bu maddelerin analizleri spektrofotometrik $(1,4,5)$, spektrofluorometrik $(6,7)$, yüksek basınçlı sıvı kormatografisi (2,3,8-10) ve gaz kromatografisi (11-14) ile yapılmaktadır. Forensik ilaç laboratuvarlarında gaz kromatografisi tekniğinden geniş ölçüde faydalanılmaktadır $(3,15,16)$.

Bu çalışmada, ilerde yapılması düşünülen fazla sayıdaki bağımlılık yapan maddelerin analizleri için güvenilir, çabuk ve pratik bir gaz kromatografik yöntemin kurulması amaçlandı. Bu amaçla cam kolonlardan daha dayanıklı olan, sabit faz olarak \% 3 OV-101 içeren cam astarlanmış tubuler çelik kolon (Glass Lined Tubular Column S/S) kullanılarak narkotik analjeziklerden meperidin, metadon ve kodein in kalitatif ve kantitatif analizleri planland.

\section{DENEL KISIM}

\section{Materyal}

Analizlerde standart olarak kullanılan meperidin hidroklorür, metadon hidroklorür, kodein fosfat ve iç standart olarak kullanılan barbital, Birleşmiş Milletler Uyuşturucu Maddelerin Kötüye Kullanılmasını Önleme Fonundan (UNFDAC) temin edildi. Standartların hazırlanmasında çözücü olarak kromatografik saflıktaki Metanol (Merck) den faydalanıldı.

\section{Metot}

\section{Gaz Sivi Kromatografisi:}

Analizlerde, alev iyonlaştırıcı dedektör (FID) bağlanmış Perkin -Elmer, 8320 Model Gaz Kromatografi cihazından faydalanıldı. Çalışmalarda kolon olarak \% 3 OV-101 ile kapl1 Chromosorb WH P (100-125 mesh) içeren cam astarlanmış tubuler çelik kolon (GLT S/S) (2m x $3.2 \mathrm{~mm}$ ) kullanıldı. Yapılan farklı çalışmalar sonunda enjektör ve dedektör sıcaklığının $290^{\circ} \mathrm{C}$ taşıyıcı gaz (azot) akış hızının $4 \mathrm{ml} / \mathrm{dk}$ ve kolon sıcaklık programlanmasında, başlangıç sıcaklığı $180^{\circ} \mathrm{C}$ de 10 
dk. kaldıktan sonra $240^{\circ} \mathrm{C}$ ye kadar $10^{\circ} / \mathrm{dk}$. artış uygulanıp son sıcaklıkta $14 \mathrm{dk}$. beklenmesinin en uygun koşullar olduğu saptandı. Çözeltiler Hamilton enjektörle $0.5 \mu 1$ enjekte edildi.

\section{Çözeltilerin hazırlanması:}

Meperidin ve metadon hidroklorürün standart stok çözeltileri $1 \mathrm{mg} / \mathrm{ml}$, kodein fosfatın ise $4 \mathrm{mg} / \mathrm{ml}$ metanol içinde hazırlandı. Bu çözeltilerden seyreltilerek çeşitli konsantrasyonlarda çözeltiler elde edildi. İç standart olarak kullanılan barbital her $\mathrm{ml}$ de $4 \mathrm{mg}$ olacak şekilde hazırlandı. Kalibrasyon eğrilerinin çizilmesi için Tablo l'de belirtilen konsantrasyonlarda mdde ve iç standart içeren $0.5 \mu$. çözelti enjekte edildi. Ağırık oranlarına karşı pik alan oranları grafiğe geçirilerek kalibrasyon eğrileri çizildi.

\section{SONUÇ VE TARTIŞMA}

Standart karışım halindeki narkotik analjeziklerden meperidin, metadon ve kodeinin \% 3 OV-101 GLT kolon kullanılarak alınan gaz kromatogramları Şekil 1 de, ilgili veriler Tablo 1'de görülmektedir.

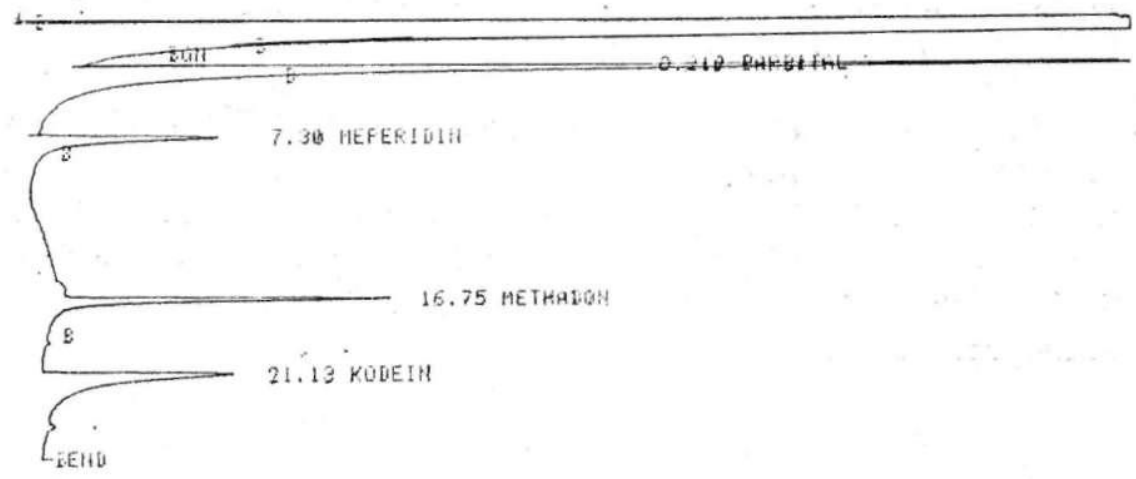

Şekil 1. Meperidin. metadon ve kodein'in karışım halindeki çözeltiden elde edilen gaz kromatogramı. 
Tablo 1. Meperidin, metadon ve kodein'in Gaz Kromatografisi ile kantitatif analiz verileri.

\begin{tabular}{|c|c|c|c|c|c|}
\hline St. mad. & $\begin{array}{l}\text { Alıkonma } \\
\text { süresi RT }\end{array}$ & Alan & $\begin{array}{c}\text { Bağ1l Alk. } \\
\text { süresi R R T }\end{array}$ & $\begin{array}{c}\text { St. çöz. } \\
\text { kons. } \mathrm{mg} / \mathrm{ml}\end{array}$ & $\begin{array}{c}\text { Miktar } \\
\text { ng/0.5 } \mu_{1}\end{array}$ \\
\hline Barbital & $\begin{array}{l}3.36 \\
3.36 \\
3.34 \\
3.35 \\
3.36\end{array}$ & $\begin{array}{l}10.7287 \\
10.9246 \\
11.1429 \\
11.1510 \\
11.1602\end{array}$ & $\begin{array}{l}1.00 \\
1.00 \\
1.00 \\
1.00 \\
1.00\end{array}$ & $\begin{array}{l}4.0000 \\
4.0000 \\
4.0000 \\
4.0000 \\
4.0000\end{array}$ & $\begin{array}{l}2000 \\
2000 \\
2000 \\
2000 \\
2000\end{array}$ \\
\hline Meperidin & $\begin{array}{l}7.47 \\
7.48 \\
7.58 \\
7.61 \\
7.58\end{array}$ & $\begin{array}{l}3.0284 \\
1.0112 \\
0.3636 \\
0.1112 \\
0.5550\end{array}$ & $\begin{array}{l}2.25 \\
2.25 \\
2.75 \\
2.76 \\
2.76\end{array}$ & $\begin{array}{l}0.2904 \\
0.1452 \\
0.0726 \\
0.0363 \\
0.0181\end{array}$ & $\begin{array}{r}145.260 \\
72.630 \\
36.315 \\
18.157 \\
9.078\end{array}$ \\
\hline Metadon & $\begin{array}{l}16.91 \\
16.95 \\
17.04 \\
17.00 \\
16.99\end{array}$ & $\begin{array}{l}4.6186 \\
2.6785 \\
1.4915 \\
0.6982 \\
0.2975\end{array}$ & $\begin{array}{l}5.12 \\
5.23 \\
5.22 \\
5.21 \\
5.20\end{array}$ & $\begin{array}{l}0.2981 \\
0.1491 \\
0.0746 \\
0.0322 \\
0.0184\end{array}$ & $\begin{array}{r}149.125 \\
74.563 \\
37.281 \\
18.645 \\
9.320\end{array}$ \\
\hline Kodein & $\begin{array}{l}21.47 \\
21.61 \\
21.62 \\
21.42 \\
21.46\end{array}$ & $\begin{array}{l}5.7774 \\
3.0109 \\
1.5583 \\
0.5583 \\
0.2915\end{array}$ & $\begin{array}{l}6.58 \\
6.70 \\
6.53 \\
6.58 \\
6.42\end{array}$ & $\begin{array}{l}1.0042 \\
0.5013 \\
0.2501 \\
0.1255 \\
0.0627\end{array}$ & $\begin{array}{r}502 \quad 200 \\
251.100 \\
125.550 \\
62.775 \\
31.388\end{array}$ \\
\hline
\end{tabular}

Meperidin, metadon ve kodeinin yapılan istatistiksel hesapları sonucunda elde edilen regresyon denklemleri sırasi ile $\mathrm{y}=4.1362 \mathrm{x}-$ $0.032, \mathrm{y}=0.015+5.7165 \mathrm{x}$ ve $\mathrm{y}=2.1594 \mathrm{x}-0.001$ olarak bulunmuştur. Kalibrasyon eğrileri Şekil 2 de, diğer istatistiksel değerler ise Tablo 2 de görülmektedir.

$\mathrm{Bu}$ çalışma sonucunda yeni bir kolon olan \%3 OV-101 sabit fazı içeren cam astarlanmış tubuler çelik kolon kullanılarak meperidin, metadon ve kodein'in nitel ve nicel analizlerinin verdiğimiz çalışma şartlarında doğru, hassas ve çabuk olarak yapılabileceği saptanmıştır. Böylece daha fazla sayıda bağımlılık yapan maddenin analizi bu yöntemle yapilabilecektir. 


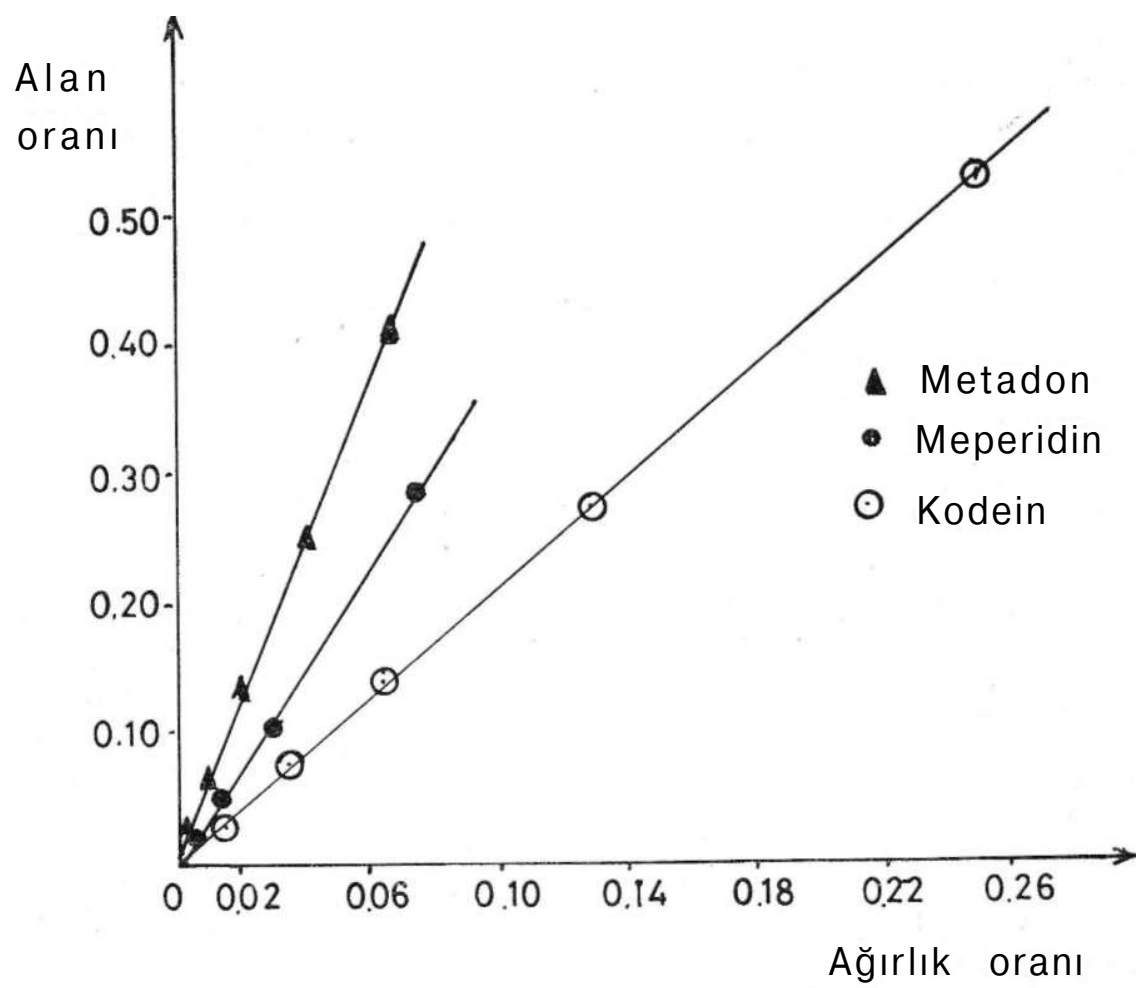

Şekil 2. Meperidin metadon ve kodeinin kalibrasyon eğrileri.

Tablo 2. Kalibrasyon eğrilerinin korelasyon ve regresyon katsayıları için yapılan istatistiksel hesapların sonuçları $\alpha=0.005, \mathrm{n}=5$ ).

\begin{tabular}{|l|c|c|c|c|c|}
\hline Madde adi & $\mathrm{b}$ & $\mathrm{r}$ & $\mathrm{Sr}$ & $\mathrm{tH}$ & $\mathrm{tT}$ \\
\hline Meperidin & 4.1362 & 0.9877 & 0.0640 & 15.4328 & 3.18 \\
Metadon & 5.7165 & 0.9962 & 0.0356 & 27.9989 & 3.18 \\
Kodein & 2.1594 & 0.9997 & 0.0100 & 99.9700 & 3.18 \\
\hline
\end{tabular}

KAYNAKLAR

1. Gill, R,, Bal, T.S., Moffat, Â.C., The Application of Derivative UV-Visible Spectroscopy in Forensic Toxicology, J. Foren, Sci. Soc. 22, 165 (1982).

2. Chashman, P.,J. Thornton, J.I., Sheman, D.L., High- Pressure Liquid Choromatographic Seperation of Phenethylamines of Forensic Interest, J. Chromatog. Sci., 11, 7 (1973). 
3. Gill, R.L.B., Maffat, A.C., High Performance Liquid Chromatography Retention Data for 84 Basic Drugs of Forensic interest on a Silica Column Using a Aqueous Methanol Eluent, J. Chromatog., 301, 165 (1934).

4. Mule, S.J., Determination of Narcotic Analgesics in Human Biological Materials: Application of Ultraviolet Spectrophotometry, Thin -Layer and Gas-Liquid Cromatography, Anal. Chem., 36, 1907 (1964).

5. Andres, C.N., Ultraviolet Absorbsion Data of Pharmaceuticals, Microgram., 1, 145 (1968).

6. Dezar, P., Canaff, R.F., Bionchi, R., Fluorimetric Characteristics of Some Narcotics and Dangerous Drugs, J. Assoc. Offic. Anal. Chem., 54, 4, (1971).

7. De Silva, J.A.F., D'Arcante, L., The use of Spectrophotofluorimetry in the Analysis of drugs in Biological Materials J. Foren, Sci., 14, 184 (1969).

8. Baker, P.B., Gough, T.A., The Seperation and Quantitation of the Narcotic Components of Illicit Heroin Using Reversed-Phase High-Performance Liquid Chromatography, J. Chromatog. Sci., 19, 483 (1981).

9. Beasley, Sr. T.H., Ziegler, H.W., High-Performance Liquid Chromatographic Analysis of Methadone Hydrocloride Oral Solution, J. Pharm Sei., 66, 1749 (1977).

10. Gupta, V.D., Ghanekar, A.G., Quantitative Determination of Codein phosphate, Guaifenesin, Pheniramine maleate, Phenyl propanolamine hydrochloride and Pyrilamine maleate in an Expectorant by High-Pressure Liquid Chromatography, J. Pharm. Sci., 66, 895 (1977).

11. Yeh, S.Y., Krebs, H.A., Thin-Layer Chromatography and Gas-Liquid Chromatography Determination of Meperidine and its Metabolites in Biological Fluids, J. Pharm. Sci. 70, 482 (1981).

12. Andrey, R.E., Moffat, A.C., Gas-Liquid Chromatographic Retention Indices of 1318 Substances of Toxicological Interest on SE-30 or OV-1 Stationary Phase, J. Chromatog., 220, 195 (1981).

13. Mule, S.J., Methods for the Analysis of Morphine and Relaten Surrogates, J. Chromatog. Sci., 12,945 (1974).

14. Hartvig, P., Fagerlund, C, A Simplified Method for the Gas-Chromatographic Determinations of Pethidine and Norpethidine After Derivatization with Trichloroethyl Chloroformate, J. Chromatog. 274, 355 (1983).

15. Gaugb, T.A., Baker, P.B., Identification of Major Drugs of Abuse Using Chromatography, J. Chromatog. Sci., 20, 289 (1981).

16. Plotczyk, L.L., Larson, P., Advances in Fused-Silica Column Tecnology for the Analysis of Underivatized Drugs, J. Chromatog, 257, 211 (1983). 